\title{
CHINESE ANTARCTIC ASTRONOMICAL OPTICAL TELESCOPES
}

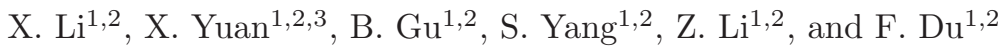

\begin{abstract}
Due to its superb seeing conditions, the Antarctica plateau is widely considered to be an excellent astronomical site. The long periods of uninterrupted darkness at polar sites such as Dome A provide a possibility of continuous observation for more than three months, which is quite suitable for time-domain astronomy. Since 2008, several wide-field optical photometric telescopes, including Chinese Small Telescope ARray (CSTAR), two of the Three Antarctic Survey Telescopes (AST3), have been deployed on Dome A. Science with these telescopes covers variable stars, supernovas, exoplanets, etc. For the remoteness of the Antarctic plateau, these telescopes are designed to observe autonomously and operate remotely via satellite communication. As for future plan, Kunlun Dark Universe Survey Telescope (KDUST), a 2.5-meter optic/infrared telescope, is being proposed as one of the two major facilities of Chinese Antarctic Observatory.
\end{abstract}

\section{RESUMEN}

Debido a sus magníficos valores de seeing, la meseta antártica es considerada como uno de los mejores emplazamientos astronómicos en la tierra. Los largos periodos de oscuridad en lugares como Dome A proporcionan la posibilidad de realizar observaciones de manera continuada por más de 3 meses, lo que es ideal para estudios astronómicos en el dominio temporal. Desde 2008, varios telescopios dedicados a fotometría óptica de gran campo, incluyendo CSTAR (Chinese Small Telescope ARray), dos de los tres telescopios antárticos dedicados a mapeo del cielo (AST3), han sido desplegados en Dome A. La ciencia que se puede realizar con estos telescopios comprende estrellas variables, supernovas, exoplanetas, etc. Debido a lo remoto de la meseta antártica, estos telescopios han sido diseñados para observar de manera autónoma y operar remotamente via comunicación por satélite. Y ya de cara al futuro, el Telescopio Kunlub dedicado al Mapeo del Universo Oscuro (KDUST), un telescopio óptico/infrarrojo de 2,5-m de diámetro, se ha propuesto como uno de los dos principales que China instalará en el Observatorio Chino Antártico.

Key Words: telescopes

\section{INTRODUCTION}

In the year of 2005, a Chinese traverse team reached Dome A $\left(80^{\circ} 25^{\prime} 03^{\prime \prime} \mathrm{S}, 77^{\circ} 05^{\prime} 32^{\prime \prime} \mathrm{E}\right)$, the highest peak of Antarctic plateau with $4093 \mathrm{~m}$ elevation, $-80^{\circ} \mathrm{C}$ lowest temperature and $586 \mathrm{hPa}$ average air pressure. Shortly after this event, the first time humans had ever been to Dome A, the Chinese Centre for Antarctic Astronomy (CCAA), jointly initiated by Chinese institutes and universities, was established in December 2006, which is dedicated to promote Chinese Antarctic astronomy observations.

In early 2008, the first generation wide-field optical photometric telescope, Chinese Small Telescope Array (CSTAR), along with PLATO and many site testing instruments was successfully in-

\footnotetext{
${ }^{1}$ National Astronomical Observatories Nanjing Institute of Astronomical Optics \& Technology, Chinese Academy of Sciences, Nanjing 210042, Chine (xyli@niaot.ac.cn).

${ }^{2}$ Key Laboratory of Astronomical Optics and Technology, Nanjing Institute of Astronomical Optics \& Technology, Chinese Academy of Sciences, Nanjing 210042, Chine.

${ }^{3}$ Chinese Center for Antarctic Astronomy, Chine.
}

stalled and operated. According to the four years site testing works jointly by Chinese Center of Antarctic Astronomy (CCAA), University of New South Wales (UNSW) and Polar Research Institute of China (PRIC), Dome A has an unrivaled observing conditions for astronomical observation from optical wavelength to thermal infrared and beyond, for its high altitude, low temperatures, minimal freeatmosphere turbulence, and a very thin surface layer (Sims et al. 2012).

Kunlun station $\left(80^{\circ} 25^{\prime} 2.42^{\prime \prime} \mathrm{S}, \quad 77^{\circ} 6^{\prime} 59.21^{\prime \prime} \mathrm{E}\right)$, about 7 kilometers away from Dome A, was established in 2009. The infrastructures at Kunlun Station can accommodate 15-20 people over summer, but it is still hardly possible for people to live through winter due to the extremely coldness in winter. In January of 2017, China's polar flight plane Snow Eagle 601 has landed on Kunlun Station, the first time for a fixed-wing aircraft in human's history. The aircraft will offer another alternative for transportation of supply for the research stations, which 


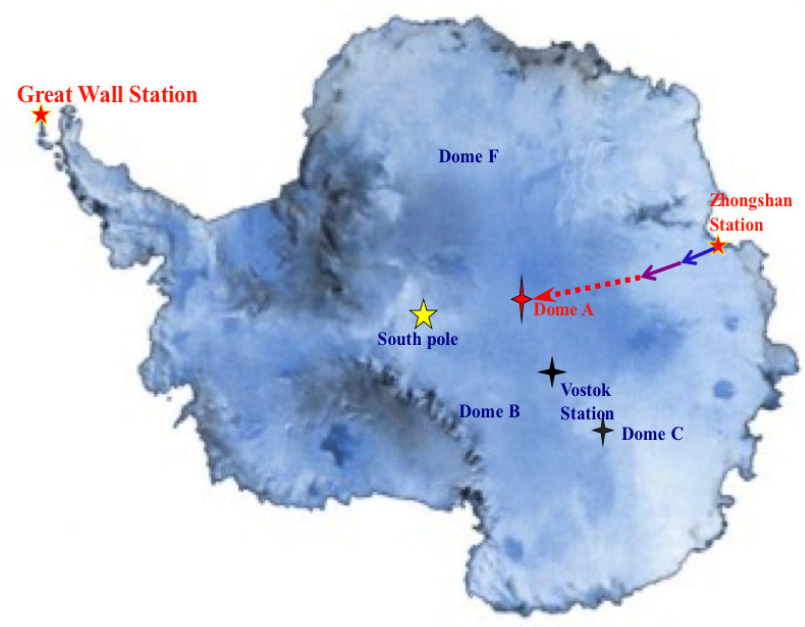

Fig. 1. Antarctic continent.

has mainly been conducted by vessel and vehicles. Compared with Kunlun Station, Zhongshan Station $\left(69^{\circ} 22\right.$ '24.91"S, $76^{\circ} 22$ '17.95"E) hasn't so good observation conditions, but it is all-year round station and can support about 25 wintering personnel. In 2016, Bright Star Survey Telescope (BSST) deloyed at Zhongshan Station collected high-cadence light curves of Proxima Centauri in August and September, which is the first astronomical observation in Zhongshan Station (Liu et al. 2018; Li, Lu, \& Yuan 2015). It's reported that there are almost 60 clear nights a year in Zhongshan station. In the future, it probably will become another regular astronomical observation site (see Figure 1).

\section{TELESCOPES}

\subsection{CSTAR}

As the first generation Chinese Antarctic telescope, Chinese Small Telescope ARray (CSTAR) was deployed on Dome A in January 2008. It is composed of four $14.5 \mathrm{~cm}$ optical telescopes, each with a different filter $(\mathrm{g}, \mathrm{r}, \mathrm{i}$ and open $), 4.5^{\circ} \times 4.5^{\circ}$ field of view (FOV) and fast $\mathrm{f} /$ ratio about 1.2. It has a fixed observing direction centered on the south celestial pole without any moving parts, including the focal plane. The layout is shown as Figure 2.

The automatic operation of CSTAR had been continuing for four consecutive winters. Industrial computers with wide working temperature range were selected for each telescope. Each computer had a flash disk for operating system and telescope control software and $750 \mathrm{G}$ hard disk for data storage. The control software automatically collected, stored or transferred images, compressed the data needed to be sent back, and completed some preliminary data

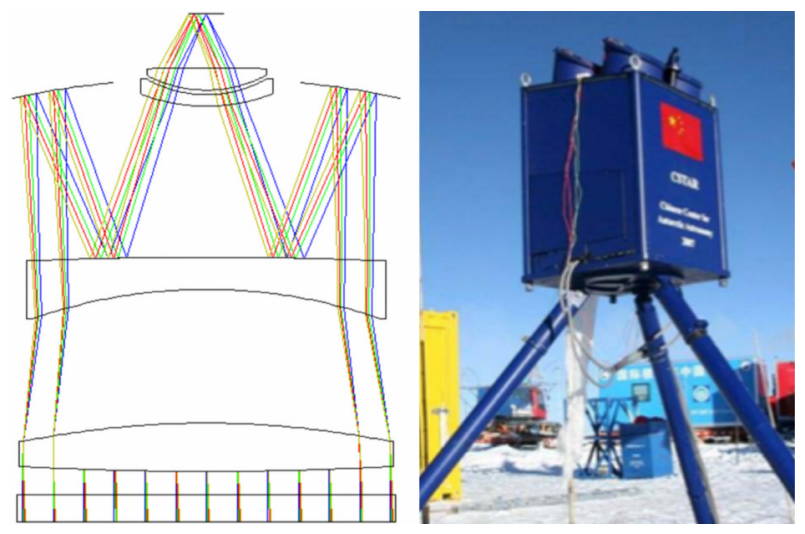

Fig. 2. Layout and CSTAR.

processing. The exposure time could be adjusted according to the observing conditions. Due to the very limited communication band, most data was stored in the hard disk and taken back by the next expedition team, and only a small subset was sent back by the Iridium satellite network.

The image quality of CSTAR is $90 \%$ of the light energy circled in 2 pixels. The limited magnitude observed is about $16.5 \mathrm{~m}$ with 20 seconds exposure time. Site testing Statistics by 4 years CSTAR data show that Dome A has a darker sky background $\left(\sim 20.5 \mathrm{mag} \operatorname{arcsec}^{-2}\right.$ at moonless clear night) than the great astronomical sites such as La Palma and Paranal etc. The cloud cover at Dome A seems also better than Mauna Kea (Zou et al. 2010). The fraction of images affected by relatively strong aurora is only about 2 . The photometric precision of CSTAR can reach 2mmag. From the CSTAR images in 2008, about 157 variable candidates were detected (Wang et al. 2011), 67 new variable candidates by 2010 data.

\subsection{AST3}

Three Antarctic Survey Telescopes (AST3) are the second-generation Chinese telescopes on Dome A. AST3 are composed of three catadioptric telescopes. The first AST3 (AST3-1) was mounted on Dome A in Jan. 2012 and removed in Jan. 2017. The second telescope (AST3-2) was deployed in Jan. 2015 and has observed for 3 winters (see Figures 3 and 4). The third one (AST3-3) is being completed and under domestic commissioning. It will join AST3-2 at the end of 2018.

The first two telescopes have $500 \mathrm{~mm}$ entrance pupil diameter, $3.73 \mathrm{f}$-ratio, and $2.92^{\circ} \times 2.92^{\circ}$ field of view, matched with i-band filter and $10 \mathrm{~K} \times 10 \mathrm{~K}$ CCD which is currently the largest single-chip CCD in the world (Cui, Yuan, \& Gong 2008). The optical system consists of a transparent aspheric plate 


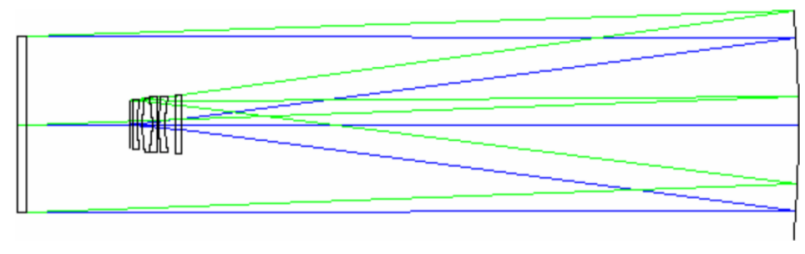

Fig. 3. Layout of the first two AST3.

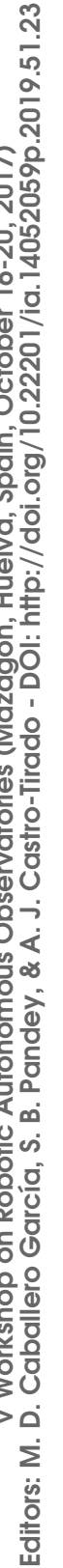

(also serve as the sealing window), an oblate primary mirror, and spherical lens correctors including atmospheric dispersion corrector before the flat focal plane. The sealing window is coated with a thin layer of Indium Tin Oxide (ITO) film, a kind of transparent conductor. When electric current flows through the ITO film, the heat is very efficient to deice the ice formation, which was also experienced by CSTAR.

The designed image quality of AST3 is $80 \%$ energy encircled in 1 arcsecond and distortion in the whole field less than 1 pixel. In order to keep the telescope properly work under temperature from $30^{\circ} \mathrm{C}$ to $-80^{\circ} \mathrm{C}$, low thermal expansion materials were used to minimize the thermal effect. Zerodur and fused silica were selected for most of AST3's optical components except for the lens-prism of the corrector. INVAR36 was selected as the material for the main structure. The mechanical and tracking components such as bearing, gear, motor, reducer and resolver must be specially developed and survived from normal temperature to $-80^{\circ} \mathrm{C}$. A motorized focusing mechanism with a stepping accuracy of 1 micron was designed to adjust the focal plane to the best position in order to compensate for the thermal effect. All movements of the telescope are all in harsh environment while other electronics are located in the warm cabin, called Plateau Observatory (PLATO).

PLATO, which was designed by University of New South Wales in Australia, provides 24V of DC voltage, $220 \mathrm{~V}$ of $\mathrm{AC}$ voltage and totally about $1 \mathrm{KW}$ of power for the whole system including the telescope, Telescope Control Computer (TCC), Observing schedule Control Computer (OCC), Pipeline, disk arrays, $\mathrm{CCD}$, webcams, meteorological tower, etc.

Time domain astronomy is quite suitable to be carried out by AST3. The main sciences for AST3 are variable stars (Wang et al. 2017), very early discovery of supernova and exoplanets searching. Using AST3, Nanjing University team finds more than 100 exoplanet candidates, which is the first time in Antarctic area. In 2017, AST3-2 was the only one telescope located in Antarctic that joined in the multi-messenger observations of GW170817 (Hu et al. 2017; Andreoni et al. 2017).

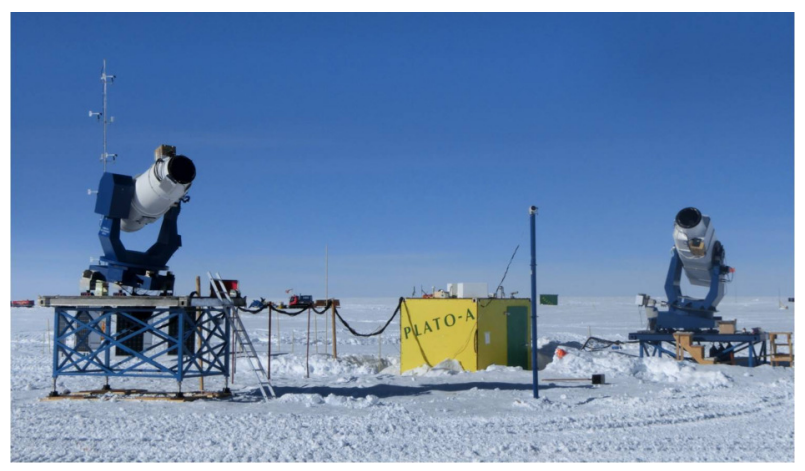

Fig. 4. AST3-1 (right) and AST3-2 (left) in 2016.

For AST3-3, a fold mirror was added to guide the focal plane outside the main optical tube which makes the CCD onsite assembly and maintenance easier and better tube seeing. By changing different correctors and detector, the third telescope can also work in near infrared aiming diffraction limited imaging in $\mathrm{K}$ band. (Lawrence et al. 2008)

\section{CHALLENGES}

Dome A has commonly clear skies and constant light winds. The average wind speed is $1.5 \mathrm{~m} / \mathrm{s}$ at $4 \mathrm{~m}$ elevation ( $\mathrm{Hu}$ et al. 2014). Snowfall is also rare, precipitation in the form of fine ice crystals, no more than a few centimeters a year. But the snow may not be falling from the sky. Occasionally, when high winds occurs, over $10 \mathrm{~m} / \mathrm{s}$, it may lead to a blizzard in which a combination of high winds and blowing snow. A blizzard may also easily lead to white-out conditions when it is impossible to see surface features, the whole world is just a big white blur. To survive the white-out conditions, tube and gear boxes should be well sealed to block pervasive snow and ice.

As it is mentioned in $\S 2.2$, ITO film with adjustable power was coated on the window mirror of the tube to make it a bit warmer than ambience, keeping the surface from icing or frosting. Blowers were also mounted alongside with the telescope to help remove snow and frost from the window.

Solar power generation is effective during the summer. While in winter there is no sun for several months, so only an engine-driven generator can provide power throughout the winter. The engine module is an essential part of the whole system and needs to run continuously. Low atmospheric pressure poses difficulties for air-cooled electronics modules and reduces the achievable power output form airbreathing engines. The generator can provide kilowatt levels of power for the entire system. 


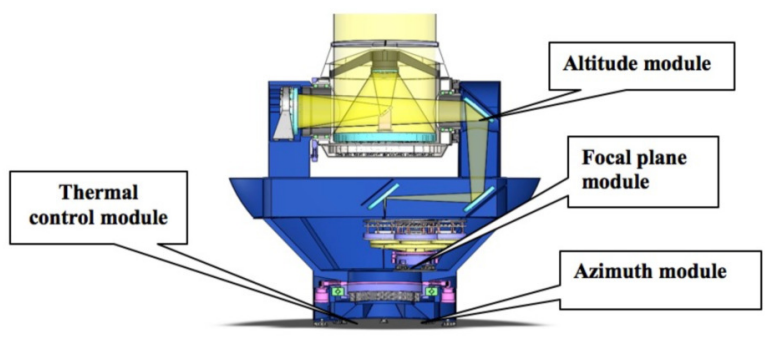

Fig. 5. KDUST 3D model.

Servicing can take place only during a brief summer period, typically for 20 days. The telescopes are designed to operate autonomously for up to 11 months at a time. So reliability, redundancy and reconfigurability are essential for all parts of the whole system.

All communication must be via satellites in non-geostationary orbits with very low bandwidth $(<128 \mathrm{kbps})$ and high costs $(\$ 10 / \mathrm{MB})$. So the facility should be in self-supported observing mode over winter under remote control. Bulk data are stored on-site and partially send back for timely analysis and follow-up purposes. Software for on-site automatic sky survey and data management have been developed and worked very well these years.

\section{FUTURE PLANS}

The whole CSTAR and AST3 projects will be good test benches for the development of future larger aperture optical infrared Antarctic telescopes such as the proposed 2.5m Kunlun Dark Universe Survey Telescope (KDUST) project. The 3D model of KDUST is shown in Figure 5.

The main specifications of KDUST are shown as following. More details are described in Zhu et al. (2014).

Diameter: $2500 \mathrm{~mm}$

Field of view: $\phi 1.5^{\circ}$

F-ratio: 9.5

Plate scale: $\sim 0.09 " / 10 \mu \mathrm{m}$

Working wavelength: $0.4 \mathrm{um} \sim 2.5 \mu \mathrm{m}$

Image quality: $80 \%<0.3$ "

Supporting tower: $\sim 15 \mathrm{~m}$

The whole proposal of Kunlun next generation astronomical observatory includes five major parts of Kunlun Dark Universe Survey Telescope (KDUST), 5m Dome A Terahertz Explorer (DATE5), Power and Energy Platform, Site Monitoring System, and Communication System.

\section{CONCLUSION}

It has been ten years since the first time astronomy have joined into Chinese Antarctica Expedition. Astronomical equipments have been installed progressively, such as PLATO, CSTAR, SNODA, GATTINI, FTS, PLATO-A, AST3-1 and AST3-2, etc. We did better understand Dome A, and get some methods to help telescopes survive the harsh conditions, even though we still have some problems urge to be solved, such as increasing energy supply and extending system life-span.

Acknowledgements: We would like to thank the Polar Research Institute of China (PRIC) for organizing the Antarctic Research Expeditions. We express our thanks to all the expedition members for providing invaluable assistance for us to install and maintain the telescopes. Also we would like to give our thanks to Australia cooperators for their great works on PLATO and PLATO-A and helpful discussions on telescope development. The authors are also grateful for the support by the National Basic Research Program of China, the Important Direction Project of Chinese Academy of Sciences (CAS) Knowledge Innovation Project, Tsinghua University and Nanjing University for their financial support.

\section{REFERENCES}

Andreoni, I., Ackley, K., Cooke, J., et al. 2017, PASA, 34,69

Cui, X., Yuan, X., \& Gong, X. 2008, SPIE, 7012, 2

Hu, Y., Shang, Z., Ashley, M. C. B., et al. 2014, PASP, 126,868

Hu, L., Wu, X., Andreoni, I., et al. 2017, SciBu, 62, 1433

Lawrence, J. S., Allen, G. R., Ashley, M. C. B., et al. 2008, SPIE, 7012, 27

Lawrence, J., Ashley, M. C. B., Burton, M., et al. 2016, SPIE, 9908, 51

Li, Z., Lu, H., \& Yuan, X. 2015, ChOpL, 13, 11

Liu, H., Jiang, P., Huang, X., et al. 2018, AJ, 155, 12

Sims, G., Ashley, M. C. B., Cui, X., et al. 2012, PASP, 124,637

Wang, L., Macri, L. M., Krisciunas, K., et al. 2011, AJ, 142,155

Wang, L., Ma, B., Li, G., et al. 2017, AJ, 153, 3

Zou, H., Zhou, X., Jiang, Z., et al. 2010, AJ, 140, 602

Zhu, Y., Wang, L., Yuan, X., et al. 2014, SPIE, 9145, 0E 